\title{
The presence of Ehrlichia canis in Rhipicephalus bursa ticks collected from ungulates in continental Eastern Europe
}

\author{
Ioana Adriana Matei ${ }^{1 凶}$, Angela Monica Ionică ${ }^{2,3}$, \\ Alexandra Corduneanu ${ }^{2}$, Cristian Domșa ${ }^{2}$, Attila D. Sándor ${ }^{2,4}$ \\ ${ }^{1}$ Department of Microbiology, Immunology and Epidemiology, \\ ${ }^{2}$ Department of Parasitology and Parasitic Diseases, Faculty of Veterinary Medicine, \\ 3"Regele Mihai I al României" Life Science Institute, \\ University of Agricultural Sciences and Veterinary Medicine, 400372 Cluj-Napoca, Romania \\ ${ }^{4}$ Department of Parasitology and Zoology, \\ University of Veterinary Medicine, H-1078 Budapest, Hungary \\ ioana.matei@usamvcluj.ro
}

Received: February 17, $2021 \quad$ Accepted: August 2, 2021

\begin{abstract}
Introduction: Rhipicephalus bursa is a common tick parasite of small-to-medium size ungulates, principally in warm, temperate, and subtropical areas. Although common in livestock and showing a wide geographic distribution, its epidemiological role in tick-borne bacterial disease is barely known. This study addressed the knowledge gap and aimed to screen for the presence of Anaplasmataceae and spotted fever group (SFG) Rickettsia species in R. bursa ticks collected from domestic animals in Romania, Eastern Europe. Material and Methods: A total of 64 pools of $R$. bursa ticks collected from small ungulates were tested by PCR for Anaplasmataceae DNA presence using group-specific primers. Specific testing was performed for Anaplasma marginale/A. centrale/A. ovis, A. platys, A. phagocytophilum, Ehrlichia canis, and SFG Rickettsia. The positive samples were purified and sequenced, and sequences analysis was used to identify the species and to confirm the PCR results. Results: The only pathogen identified in this study was E. canis. The obtained sequences confirmed the PCR results. The presence of $E$. canis in $R$. bursa in Romania and in ticks from sheep was shown for the first time in this study. Conclusion: Based on these findings, it may be presumed that the E. canis DNA originated from ticks; however, the vectorial role of $R$. bursa (and other arthropod species) in the transmission of E. canis should be proved experimentally.
\end{abstract}

Keywords: Anaplasmataceae, spotted fever group Rickettsia, Ixodidae, livestock, tick-borne diseases.

\section{Introduction}

The genus Rhipicephalus is the second most speciose in the Ixodidae family, with 74 species recognised worldwide (31). Most species have a tropical or subtropical distribution, with colder regions hosting only a few representatives. Rhipicephalus bursa is one of the few species occurring in temperate regions, being the only exophilic Rhipicephalus species reaching middle latitudes in Europe (30). It is largely distributed in the Mediterranean, occurring in the Palearctic region between the latitudes of $31^{\circ}$ and $45^{\circ} \mathrm{N}$ (31). Rhipicephalus bursa prefers the warmer, grassy slopes of low-altitude mountains, drier lowlands or semi-desert environments (20). However, recently it has also been recorded in colder regions, implying a potential tendency to spread to the north (1). In Romania, R. bursa is distributed in the southern lowland region, but there are also sporadic reports from central and north-western parts, suggesting a possible human-mediated colonisation through livestock transfers (15). It is a two-host tick of which the immature stages commonly infest the same host and the adults a different one. The usual hosts are livestock (goats, sheep, cattle and horses), but rarely they may be other mammals, birds, lizards and snakes (31). It was also recorded in free-living carnivores and wild 
ungulates (30), but its presence is sporadic in nondomesticated species, at least in Eastern Europe. Human infestations are rare but possible, and were also reported locally (15).

The vectorial role of $R$. bursa is not as well known as that of other Rhipicephalus species (e.g. R. sanguineus (6)). It was recognised as a vector of Babesia ovis (8) and Coxiella burnetii (20). However, several other pathogens such as Theileria spp., Anaplasma marginale, A. ovis and Ehrlichia canis were reported in R. bursa $(10,13,23,31)$.

Ehrlichia is one genus of obligate intracellular parasitic bacteria transmitted mainly by ticks from one host to another, and Anaplasma and Rickettsia are two further significant genera of with tick vectors. They have a wide geographical distribution and are important disease-causing agents in livestock, pets and humans (24). These bacteria may infect different haematopoietic cells, causing persistent infections in many vertebrate hosts and thus having many zoonotic reservoirs in nature (21). The most common bacterial species causing infections in domestic animals are A. phagocytophilum, A. marginale, $A$. centrale, and $A$. ovis, and less involved species are several of the Ehrlichia and spotted fever group (SFG) Rickettsia $(5,29)$. The management of these infections and generally of vector-borne diseases requires an appropriate understanding of their epidemiology in possible endemic areas. Knowledge of the presence of infectious agents in $R$. bursa ticks and the possible epidemiological role of this species in tick-borne diseases is scant in Eastern Europe, although this species is a common parasite of domestic ungulates (15). The aim of this study was to screen for the presence and the prevalence of rickettsial agents in $R$. bursa ticks collected from domestic livestock in south-eastern Romania, an area where this tick is commonly found.

\section{Material and Methods}

The tick sampling took place in June 2016 in southeastern Romania; Fig. 1. presents the distribution of collection locations. Ticks were collected from sheep (Ovis aries) and goats (Capra hircus) kept in mixed flocks, foraging on extensive pastures. The ixodids were morphologically identified based on common features of dichotomous keys (31) and stored in 70\% ethanol at $-20^{\circ} \mathrm{C}$ until examination.

Genomic DNA was extracted from pools of $R$. bursa ticks (one pool per host) using commercial ISOLATE II Genomic DNA Kits (Bioline, London, UK), following the manufacturer's instructions. In order to assess cross-contamination between extracts, negative controls consisting of reaction mixes without DNA were used in each extraction procedure. The DNA quantity and purity were assessed using an ND-1000 spectrophotometer (NanoDrop Technologies, Wilmington, DE, USA), based on a representative number of randomly selected samples.

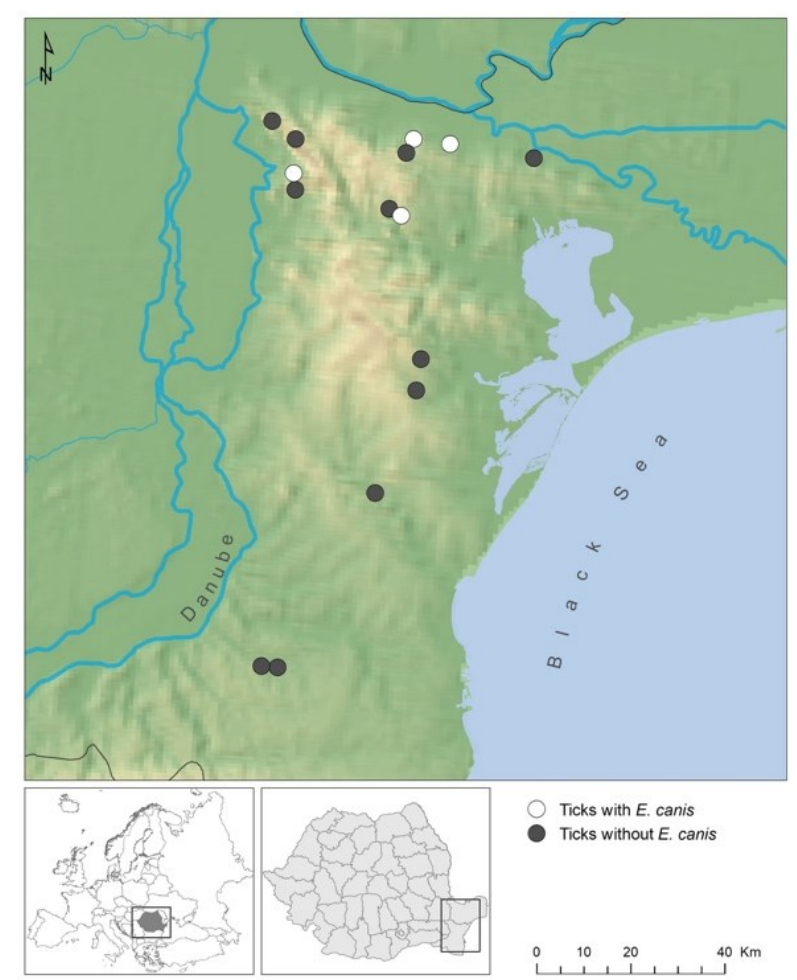

Fig. 1. Geographical origin of Rhipicephalus bursa (total collected and Ehrlichia-positive) in south-eastern Romania

The samples were assessed for the presence of Rickettsiales bacteria using general and specific primers. The first PCR was performed with EHR16SD and EHR16SR general primers (Macrogen Europe B.V., Amsterdam, the Netherlands) flanking a $345 \mathrm{bp}$ fragment of 16S rRNA ( $r r s$ ) of various species including Ehrlichia canis, E. chaffeensis, E. muris, Cowdria ruminantium, A. phagocytophilum, A. platys, A. marginale, A. centrale, Wolbachia pipientis, Neorickettsia sennetsu, $N$. risticii, and $N$. helminthoeca following the protocol developed by Parola et al. (19). Genus and species specific PCRs were performed using two nested PCRs: first using Ge3a and Ge10 primers (Macrogen Europe B.V., Amsterdam, the Netherlands) amplifying a 932 bp fragment of rrs of Anaplasma spp., and Ge2 and Ge9 primers (Macrogen Europe B.V., Amsterdam, the Netherlands) amplifying a $546 \mathrm{bp}$ fragment of $r r s$ of A. phagocytophilum, as described and used by Massung et al. (14) and the second using ECC and ECB primers (Macrogen Europe B.V., Amsterdam, the Netherlands) flanking a $500 \mathrm{bp}$ rrs fragment of Ehrlichia spp., and respectively Canis and HE3 primers (Macrogen Europe B.V., Amsterdam, the Netherlands) flanking a 389 bp rrs fragments of E. canis as detailed in Siarkou et al. (27).

Conventional PCRs were employed for A. platys using specific EPLAT5 and EPLAT3 primers (Macrogen Europe B.V., Amsterdam, the Netherlands) targeting a $359 \mathrm{bp}$ fragment of the $r r s$ gene (18), and for A. marginale/A. centrale/A. ovis using Msp43 and Msp45 primers targeting an 842 bp fragment of the $m s p 4$ gene (7). The samples were also assessed for the presence of SFG Rickettsia using group-specific 
Rsfg877 and Rsfg1258 primers (Macrogen Europe B.V., Amsterdam, the Netherlands) targeting a $359 \mathrm{bp}$ fragment of the gltA gene (22). Table 1 lists all the primers used.

The amplification was performed with $25 \mu \mathrm{L}$ of reaction mixture containing $12.5 \mu \mathrm{L}$ of Green PCR Master Mix (Rovalab GmBH, Teltow, Germany), $6.5 \mu \mathrm{L}$ of PCR water and $1 \mu \mathrm{L}$ of each primer $(0.01 \mathrm{mM})$ and a $4 \mu \mathrm{L}$ aliquot of isolated DNA. One $\mu \mathrm{L}$ of the primary PCR products was used in the nPCR reaction. In each PCR reaction set, positive and negative controls were included in order to assess the specificity of the reaction and the possible presence of cross-contamination. Positive controls consisted of DNA extracted from the blood of two dogs naturally infected with $A$. phagocytophilum and E. canis, and from Ixodes ricinus infected with Rickettsia helvetica, all previously confirmed by sequencing. The negative control consisted of a reaction mix without DNA. The PCR was carried out using a T100 Thermal Cycler (Bio-Rad, Hercules, CA, USA) using protocols described in the literature $(7,18,19,22$, 27). PCR products were visualised by electrophoresis in a $1.5 \%$ agarose gel stained with SYBR Safe DNA gel stain (Invitrogen, part of Thermo-Fisher Scientific, Waltham, MA, USA). All positive PCR products were purified using a QIAquick PCR Purification Kit (Qiagen, Hilden, Germany). Sequencing analysis was performed by a commercial provider (Macrogen Europe, Amsterdam, the Netherlands) and the obtained sequences were compared with those available in GenBank by basic local alignment search tool analysis. Statistical calculations were performed using Epi Info 7 software (CDC, Atlanta, GA, USA). A phylogenetic tree was constructed based on the maximum parsimony method, a bootstrap test with 1,000 replicates was carried out according to the Subtree-PruningRegrafting algorithm in MEGA6 software (28), and the percentage of replicate trees in which the associated taxa are clustered together in the bootstrap test was calculated. The phylogenetic branches were $>50 \%$ supported by bootstrap analysis. The Anaplasma platys sequence was used as the outgroup.

\section{Results}

Altogether, 88 domestic ruminants comprising 43 goats and 45 sheep belonging to 14 flocks were inspected for the presence of ticks. Ticks were found on animals from 13 of the flocks, with a mean tick prevalence of $92.04 \%, 100 \%$ prevalence in goats and $84.44 \%$ in sheep. Two tick species were found, $R$. bursa accounting for $98.3 \%$ of all ticks collected, and Hyalomma marginatum making up the remaining 1.7\% and having $14.8 \%$ prevalence. All R. bursa individuals were adults and the male/female ratio was 1:4. Overall, 7 out of 64 pools of ticks (10.94\%, CI 95\%: 4.51-21.25) were positive for Anaplasmataceae DNA (Fig. 2). All these seven samples were positive for Ehrlichia spp. and for $E$. canis. The remaining tested pathogens were not amplified in any of the samples. The positive ticks originated from both sheep and goats, in which prevalences were $8.7 \%(2 / 23$; CI 95\%: 1.07-28.04) and $12.2 \%$ (5/41, CI 95\%: 4.51-21.25), respectively. The animals carrying positive ticks originated from four different locations, and in one (Teliţa) both sheep and goats infested with positive ticks were found.

Among the obtained sequences, six were identical and revealed a $100 \%$ similarity to other $E$. canis isolates (Fig. 3), including those from dogs in Brazil (GenBank accession no. JX437966), Tunisia (accession no. EU781689) or India (accession no. KF888021) and a tick from Brazil (accession no. KF972452). The seventh sequence differed by one nucleotide and was $100 \%$ identical to three isolates from Brazil (accession nos KP642753, KF972452 and JQ260853). The obtained sequences were deposited in GenBank under accession nos MG241316 and MG241317.

Table 1. Primers used for the detection of Rickettsiales DNA in Rhipicephalus bursa

\begin{tabular}{|c|c|c|c|c|}
\hline Pathogen & Primer sequence & Target gene & $\begin{array}{c}\text { Target fragment } \\
\text { length }\end{array}$ & Reference \\
\hline Anaplasmataceae & $\begin{array}{l}\text { EHR16SD: GGTACCYACAGAAGAAGTCC } \\
\text { EHR16SR: TAGCACTCATCGTTTACAGC }\end{array}$ & 16S rRNA & $345 b p$ & 19 \\
\hline $\begin{array}{l}\text { Anaplasma } \text { spp./ } \\
\text { A. phagocytophilum }\end{array}$ & $\begin{array}{l}\text { Ge3a: CACATGCAAGTCGAACGGATTATTC } \\
\text { Ge10: TTCCGTTAAGAAGGATCTAATCTCC } \\
\text { Ge2: AACGGATTATTCTTTATAGCTTGCT } \\
\text { Ge9: GGCAGTATTAAAAGCAGCTCCAGG }\end{array}$ & $16 \mathrm{~S}$ rRNA & $\begin{array}{l}932 \mathrm{bp} \\
546 \mathrm{bp}\end{array}$ & 14 \\
\hline $\begin{array}{l}\text { Ehrlichia spp./ } \\
\text { E. canis }\end{array}$ & $\begin{array}{l}\text { ECC: AGAACGAACGCTGGCGGCAAGCC } \\
\text { ECB: CGTATTACCGCGGCTGCTGGCA } \\
\text { Canis: CAATTATTTATAGCCTCTGGCTATAGGA } \\
\text { HE3: TATAGGTACCGTCATTATCTTCCCTAT }\end{array}$ & 16S rRNA & $\begin{array}{l}500 \mathrm{bp} \\
389 \mathrm{bp}\end{array}$ & 27 \\
\hline $\begin{array}{l}\text { A. marginale/ } \\
\text { A. centrale/A. ovis }\end{array}$ & $\begin{array}{l}\text { Msp43: CCGGATCCTTAGCTGAACAGGAATCTTGC } \\
\text { Msp45: GGGAGCTCCTATGAATTACAGAGAATTGTTTAC }\end{array}$ & msp4 & $842 \mathrm{bp}$ & 7 \\
\hline A. platys & $\begin{array}{l}\text { EPLAT5: TTTGTCGTAGCTTGCTATGAT } \\
\text { EPLAT3: CTTCTGTGGGTACCGTC }\end{array}$ & 16S rRNA & $359 \mathrm{bp}$ & 18 \\
\hline SFG Rickettsia spp. & $\begin{array}{l}\text { Rsfg877: GGGGGCCTGCT- CACGGCGG } \\
\text { Rsfg1258: ATTGCAAAAAGTACAGTGAACA }\end{array}$ & gltA & $359 \mathrm{bp}$ & 22 \\
\hline
\end{tabular}




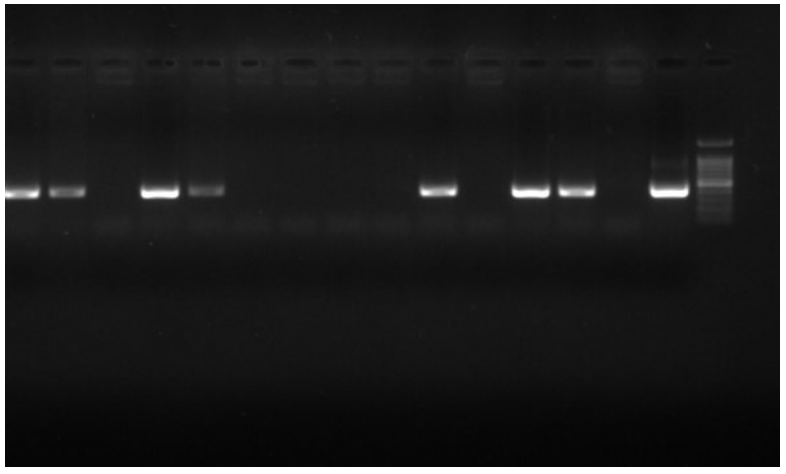

Fig. 2. Electrophoresis gel image showing positive results and including negative and positive controls and the 100-bp DNA ladder (Invitrogen, part of Thermo-Fisher Scientific, Waltham, MA, USA) as the last 3 lanes

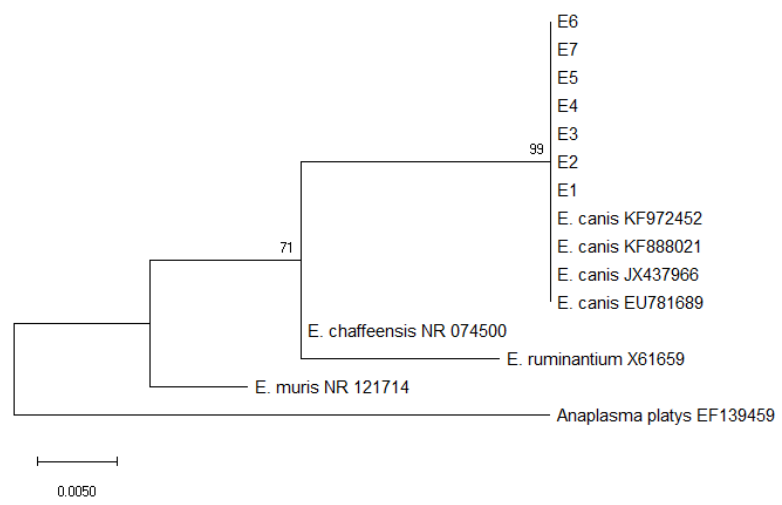

Fig. 3. Phylogenetic tree of E. canis detected in R. bursa collected from sheep and goats in south-eastern Romania

\section{Discussion}

The study results show the presence of E. canis in $R$. bursa in Romania for the first time. Moreover, to the best of our knowledge this is the first report of $E$. canis in $R$. bursa collected from sheep, this bacterium having been reported in $R$. bursa collected from goats in Sardinia, Italy (13) and in the same ixodids collected from a cow on Corsica, France (5).

In Europe, the main vector for E. canis is another representative of the Rhipicephalus genus, the brown dog tick, Rhipicephalus sanguineus sensu lato (s.l.). All European countries bordering the Mediterranean are endemic for E. canis. However, some surveys have indicated that the infectious agent is spreading to countries lying to the north (25). In Romania, E. canis was identified for the first time in ticks ( $R$. sanguineus s.l.) from the south-east in 2013 (11) and later from a dog in the west (17). Before these reports, the only serological proofs of canine ehrlichiosis were published in south-eastern Romania, in an area partly overlapping with our study site (16). Infection with E. canis is reported commonly in dogs worldwide (25). Also, the infection was reported in other wild canids (foxes, wolves, raccoons, black-backed jackals and bush dogs) but experimental infection failed in other mammalian groups and positive infection cycles were only registered in domestic dogs $(2,25)$. Several studies reported the presence of $E$. canis DNA in cats and wild felids from Brazil, Portugal, Zimbabwe and Japan $(2,25)$. To the best of our knowledge, this DNA has not been reported up to now in ticks hosted by small ruminants in continental Europe, although it has already been isolated from one individual $R$. bursa tick collected from a cow, signifying prevalence of $0.8 \%$, on the island of Corsica, France (5). In addition, Masala et al. (13) detected E. canis DNA in ticks collected from goats in one location on the neighbouring island of Sardinia, also in a highly localised manner. The presence of this bacteria was recorded in low prevalence $(2.2 \%)$ in certain wild ungulates in China (12), but how the infection was acquired by these animals was not speculated upon. Furthermore, R. bursa ticks were found to commonly host other Ehrlichia spp. On Corsica, DNA of several Ehrlichia spp. (E. minasensis, Candidatus E. urmitei, and the potential new species Candidatus E. corsicanum) were recorded (3), although in low prevalence. In contrast, in this study a high prevalence of $E$. canis DNA was found in $R$. bursa ticks, and its geographical distribution in south-eastern Romania shows a more common and widespread presence of this pathogen (Fig. 1). While $R$. sanguineus s.l. (including $R$. rossicus), the proven vector of this pathogen, is widespread in dogs and wild carnivores in the region $(4,26)$, this study failed to document the presence of either of these two species in domestic herbivores. In this context it may be presumed that the E. canis DNA detected in ticks in the current study did not originate from another Rhipicephalus tick species but from $R$. bursa, suggesting a potential vectorial or reservoir role for this species for $E$. canis. However, the role of $R$. bursa and other arthropod species in the transmission of $E$. canis remains unknown, with only $R$. sanguineus s.l. being a proven vector. Rhipicephalus bursa is a common and important ectoparasite of sheep and goats in the Mediterranean basin (31), occasionally infesting carnivores and humans (15). Against the background of the high reported prevalence of $E$. canis DNA in livestock, the common occurrence of $R$. bursa in livestock warrants further investigations in order to elucidate its potential vectorial role for E. canis.

Conflict of Interests Statement: The authors declare that there is no conflict of interests regarding the publication of this article.

Financial Disclosure Statement: This study was supported by the CNCS-UEFISCDI Grant Agency of Romania (grant numbers PN-II-RU-TE-2014-4-0919: TE/36/2015 and PN-III-P1-1.1-PD-2016-0527: PD/34/2018). ADS was supported by the János Bolyai Research Scholarship of the Hungarian Academy of Science and the ÚNKP 19-4-ÁTE-10 New National Excellence Program of the MIT and NKFIH 132794.

Animal Rights Statement: None required. 


\section{References}

1. Akimov I.A., Nebogatkin I.V.: Ticks of the Genus Rhipicephalus (Acari, Ixodidae) and Their Distribution in Ukraine. Vestn Zool 2013, 47, 28-34, doi: 10.2478/vzoo-2013-0022.

2. André M.R.: Diversity of Anaplasma and Ehrlichia/Neoehrlichia agents in terrestrial wild carnivores worldwide: implications for human and domestic animal health and wildlife conservation. Front Vet Sci 2018, 5, 293, doi: 10.3389/fvets.2018.00293.

3. Cicculli V., DeCarreaux D., Ayhan N., Casabianca F., de Lamballerie X., Charrel R., Falchi A.: Molecular screening of Anaplasmataceae in ticks collected from cattle in Corsica, France. Exp Appl Acarol 2020, 81, 561-574, doi: 10.1007/s10493-02000527-w.

4. D'Amico G., Dumitrache M.O., Matei I.A., Ionică A.M., Gherman C.M., Sándor A.D., Modrý D., Mihalca A.D.: Ixodid ticks parasitizing wild carnivores in Romania. Exp Appl Acarol 2017, 71, 139-149, doi: 10.1007/s10493-017-0108-z.

5. Dahmani M., Davoust B., Tahir D., Raoult D., Fenollar F., Mediannikov O.: Molecular investigation and phylogeny of Anaplasmataceae species infecting domestic animals and ticks in Corsica, France. Parasit Vectors 2017, 10, 302, doi: 10.1186/s13071-017-2233-2.

6. Dantas-Torres F., Otranto D.: Further thoughts on the taxonomy and vector role of Rhipicephalus sanguineus group ticks. Vet Parasitol 2015, 208, 9-13, doi: 10.1016/j.vetpar.2014.12.014.

7. De la Fuente J., Van Den Bussche R.A., Garcia-Garcia J.C., Rodríguez S.D., García M.A., Guglielmone A.A., Mangold A.J., Friche Passos L.M., Barbosa Ribeiro M.F., Blouin E.F., Kocan K.M.: Phylogeography of New World isolates of Anaplasma marginale based on major surface protein sequences. Vet Microbiol 2002, 88, 275-285, doi: 10.1016/S03781135(02)00122-0.

8. Enayati A.A., Asgarian F., Sharif M., Boujhmehrani H., Amouei A., Vahedi N., Boudaghi B., Piazak N., Hemingway J.: Propetamphos resistance in Rhipicephalus bursa (Acari, Ixodidae). Vet Parasitol 2009, 162, 135-141, doi: 10.1016/j.vetpar.2009.02.005.

9. Estrada- Peña A., Farkas R., Jaenson T.G.T., Koenen F., Madder M., Pascucci I., Salman M., Tarrés-Call J., Jongejan F.: Association of environmental traits with the geographic ranges of ticks (Acari: Ixodidae) of medical and veterinary importance in the western Palearctic. A digital data set. Exp Appl Acarol 2013, 59, 351-366, doi: 10.1007/s10493-012-9600-7.

10. Ferrolho J., Antunes S., Santos A.S., Velez R., Padre L., Cabezas-Cruz A., Santos-Silva M.M., Domingos A.: Detection and phylogenetic characterization of Theileria spp. and Anaplasma marginale in Rhipicephalus bursa in Portugal. Ticks Tick Borne Dis 2016, 7, 443-448, doi: 10.1016/j.ttbdis.2016.01.004.

11. Ionita M., Mitrea I.L., Pfister K., Hamel D., Silaghi C.: Molecular evidence for bacterial and protozoan pathogens in hard ticks from Romania. Vet Parasitol 2013, 196, 71-76, doi: 10.1016/j.vetpar.2013.01.016.

12. Li Y., Chen Z., Liu Z., Liu J., Yang J., Li Q., Li Y., Luo J., Yin H.: Molecular Survey of Anaplasma and Ehrlichia of Red Deer and Sika Deer in Gansu, China in 2013. Transbound Emerg Dis 2016, 63, e228-e236, doi: 10.1111/tbed.12335.

13. Masala G., Chisu V., Foxi C., Socolovschi C., Raoult D., Parola P.: First detection of Ehrlichia canis in Rhipicephalus bursa ticks in Sardinia, Italy. Ticks Tick Borne Dis 2012, 3, 396-397, doi: 10.1016/j.ttbdis.2012.10.006.

14. Massung R.F., Slater K., Owens J.H., Nicholson W.L., Mather T.N., Solberg V.B., Olson J.G.: Nested PCR assay for detection of granulocytic ehrlichiae. J Clin Microbiol 1998, 36, 1090-1095, doi: 10.1128/JCM.36.4.1090-1095.1998.

15. Mihalca A.D., Dumitrache M.O., Magdaş C., Gherman C.M., Domşa C., Mircean V., Ghira I. V., Pocora V., Ionescu D.T., Barabási S.S., Cozma V., Sándor A.D.: Synopsis of the hard ticks (Acari: Ixodidae) of Romania with update on host associations and geographical distribution. Exp Appl Acarol 2012, 58, 183-206, doi: 10.1007/s10493-012-9566-5.

16. Mircean V., Dumitrache M.O., Györke A., Pantchev N., Jodies R., Mihalca A.D., Cozma V.: Seroprevalence and geographic distribution of Dirofilaria immitis and tick-borne infections (Anaplasma phagocytophilum, Borrelia burgdorferi sensu lato, and Ehrlichia canis) in dogs from Romania. Vector-Borne Zoonotic Dis 2012, 12, 595-604, doi: 10.1089/vbz.2011.0915.

17. Morar D., Dărăbuș G., Imre M., Ilie M.S., Imre K.: First record of autochthonous canine ehrlichiosis caused by Ehrlichia canis in Romania. Vet Clin Pathol 2015, 44, 200-204, doi: 10.1111/vcp. 12252 .

18. Murphy G.L., Ewing S.A., Whitworth L.C., Fox J.C., Kocan A.A.: A molecular and serologic survey of Ehrlichia canis, E. chaffeensis, and E. ewingii in dogs and ticks from Oklahoma. Vet Parasitol 1998, 79, 325-339, doi: 10.1016/s03044017(98)00179-4.

19. Parola P., Roux V., Camicas J.L., Baradji I., Brouqui P., Raoult D.: Detection of ehrlichiae in African ticks by polymerase chain reaction. Trans R Soc Trop Med Hyg 2000, 94, 707-708, doi: 10.1016/s0035-9203(00)90243-8

20. Raele D.A., Galante D., Pugliese N., De Simone E., Cafiero M.A.: Coxiella-like endosymbiont associated to the "Anatolian brown tick" Rhipicephalus bursa in Southern Italy. Microbes Infect 2015, 17, 799-805, doi: 10.1016/j.micinf.2015.09.011.

21. Rar V., Golovljova I.: Anaplasma, Ehrlichia, and "Candidatus Neoehrlichia" bacteria: Pathogenicity, biodiversity, and molecular genetic characteristics, a review. Infect Genet Evol 2011, 11, 1842-1861, doi: 10.1016/j.meegid.2011.09.019.

22. Regnery R.L., Spruill C.L., Plikaytis B.D.: Genotypic identification of rickettsiae and estimation of intraspecies sequence divergence for portions of two rickettsial genes. J Bacteriol 1991, 173, 1576-1589, doi: 10.1128/jb.173.5.15761589.1991.

23. Renneker S., Abdo J., Salih D.E.A., Karagenç T., Bilgiç H., Torina A., Oliva A.G., Campos J., Kullmann B., Ahmed J., Seitzer U.: Can Anaplasma ovis in small ruminants be neglected any longer? Transbound Emerg Dis 2013, 60, 105-112, doi.org/10.1111/tbed.12149.

24. Rikihisa Y.: New findings on members of the family Anaplasmataceae of veterinary importance. Ann NY Acad Sci 2006, 1078, 438-445, doi: 10.1196/annals.1374.083.

25. Sainz Á., Roura X., Miró G., Estrada-Peña A., Kohn B., Harrus S., Solano-Gallego L.: Guideline for veterinary practitioners on canine ehrlichiosis and anaplasmosis in Europe. Parasit Vectors 2015, 8, 75, doi: 10.1186/s13071-015-0649-0.

26. Sándor A.D., Dumitrache M.O., D'Amico G., Kiss B.J., Mihalca A.D.: Rhipicephalus rossicus and not $R$. sanguineus is the dominant tick species of dogs in the wetlands of the Danube Delta, Romania. Vet Parasitol 2014, 204, 430-432, doi: 10.1016/j.vetpar.2014.05.005.

27. Siarkou V.I., Mylonakis M.E., Bourtzi-Hatzopoulou E., Koutinas A.F.: Sequence and phylogenetic analysis of the 16S rRNA gene of Ehrlichia canis strains in dogs with clinical monocytic ehrlichiosis. Vet Microbiol 2007, 125, 304-312, doi: 10.1016/j.vetmic.2007.05.021.

28. Tamura K., Stecher G., Peterson D., Filipski A., Kumar S.: MEGA6: Molecular Evolutionary Genetics Analysis version 6.0. Mol Biol Evol 2013, 30, 2725-2729, doi: 10.1093/molbev/mst197.

29. Tomassone L., Portillo A., Nováková M., De Sousa R., Oteo J.A.: Neglected aspects of tick-borne rickettsioses. Parasite Vector 2018, 11, 263, doi: 10.1186/s13071-018-2856-y.

30. Vatansever Z.: Rhipicephalus bursa Canestrini and Fanzago, 1878. In: Ticks of Europe and North Africa: a guide to species identification, edited by A. Estrada-Peña, A.D. Mihalca, T.N. Petney, Springer, Cham, 2018, pp. 299-304.

31. Walker J.B., Keirans J.E., Horak I.G.: The genus Rhipicephalus (Acari, Ixodidae): a guide to the brown ticks of the world. Cambridge University Press, New York, 2005. 